\title{
CD55 polymorphisms and risk of aspirin-exacerbated respiratory disease
}

\author{
JIN SOL LEE ${ }^{1 *}$, JOON SEOL BAE $^{1 *}$, JEONG-HYUN KIM $^{1}$, JASON YONGHA KIM $^{1}$, TAE JOON PARK ${ }^{1}$, \\ CHARISSE FLERIDA PASAJE ${ }^{1}$, BYUNG-LAE PARK ${ }^{2}$, HYUN SUB CHEONG $^{2}$, SOO-TAEK UH ${ }^{3}$, \\ AN-SOO JANG ${ }^{4}$, INSEON S. CHOI ${ }^{5}$, CHOON-SIK PARK $^{3}$ and HYOUNG DOO SHIN ${ }^{1,2}$
}

${ }^{1}$ Department of Life Science, Sogang University, Seoul 121-742; ${ }^{2}$ Department of Genetic Epidemiology, SNP Genetics, Inc., Seoul 153-801; ${ }^{3}$ Division of Allergy and Respiratory Medicine, Soonchunhyang University Seoul Hospital, Seoul 140-743;

${ }^{4}$ Genome Research Center for Allergy and Respiratory Disease, Soonchunhyang University Bucheon Hospital, Bucheon 420-767; 5 Department of Allergy, Chonnam National University Medical School and

Research Institute of Medical Sciences, Gwangju 501-757, Republic of Korea

Received March 21, 2012; Accepted August 1, 2012

DOI: $10.3892 / \mathrm{mmr} .2012 .1064$

\begin{abstract}
Aspirin-exacerbated respiratory disease (AERD) is a respiratory disease characterized by acute bronchial responses upon the administration of non-steroidal anti-inflammatory drugs (NSAIDs) and the immune response by mast cells is regarded as one of the noteworthy causes of AERD pathogenesis. The complement cascade is regarded as a key mechanism for clearing pathogens from the host. CD55 is one of the proteins involved in self-recognition, a central component of the complement system and autoimmunity. To investigate the associations between CD55 single nucleotide polymorphisms (SNPs) and the risk of AERD, we carried out logistic analyses with three genetic models and further regression analysis was performed with the fall rate of forced expiratory volume in $1 \sec \left(\mathrm{FEV}_{1}\right)$ by aspirin provocation. However, our results demonstrate that no CD55 polymorphisms are associated with the risk of AERD and the fall rate of $\mathrm{FEV}_{1}(\mathrm{P}>0.05)$. Therefore, our results suggest that $C D 55$ polymorphisms are not genetic markers of aspirin-induced bronchospasm, including $\mathrm{FEV}_{1}$, in the population studied. Although the genetic role of $C D 55$ has been found to be integral to human immunity, our results indi-
\end{abstract}

Correspondence to: Dr Hyoung Doo Shin, Department of Life Science, Sogang University, 1 Shinsu-dong, Mapo-gu, Seoul 121-742, Republic of Korea

E-mail: hdshin@sogang.ac.kr

Dr Choon-Sik Park, Division of Allergy and Respiratory Medicine, Soonchunhyang University Seoul Hospital, 22 Daesagwan-gil, Yongsan-gu, Seoul 140-743, Republic of Korea

E-mail: schalr@schbc.ac.kr

*Contributed equally

Key words: aspirin-exacerbated respiratory disease, aspirintolerant asthma, $C D 55$, polymorphisms, haplotypes cate that genetic variations of CD55 do not influence the risk of AERD and the fall rate of $\mathrm{FEV}_{1}$ in the population studied.

\section{Introduction}

Aspirin-exacerbated respiratory disease (AERD) is a chronic bronchial response to oral intake of non-steroidal anti-inflammatory drugs (NSAIDs), including aspirin (1). The symptoms of AERD include aspirin sensitivity, bronchial asthma and chronic rhinosinusitis with nasal polyposis (2-4). Approximately $20 \%$ of adult asthmatics are known to have aspirin intolerance (5). Thus, AERD is considered as a major health issue in the epidemiology of asthma.

A hypothesis for AERD pathogenesis states that the cyclooxygenase (COX)-1 enzyme is inhibited by NSAIDs, including aspirin, resulting in a decrease in the level of prostaglandin (PG)-E2 (5). Furthermore, the decreased amount of PG-E2 induces histamine release from mast cells that may influence aspirin sensitivity and induce the production of leukotrienes in the 5-lipoxygenase pathway (5).

CD55, also known as decay accelerating factor (DAF), is a membrane protein that is associated with the complement system. In the innate and adaptive immunity, the complement system plays a key role as a biochemical cascade, clearing pathogens from the host. However, the complement system is also able to cause critical damage to the host cell and this leads to immune diseases affecting the host, including asthma. The complement system is tightly regulated by several complement control proteins including the membrane cofactor protein (MCP), C4b-binding protein (C4BP), factor $\mathrm{H}(\mathrm{fH})$ and CD55. Among the complement control proteins, CD55 plays a key role in the regulation of the complement system by preventing the assembly of the $\mathrm{C} 3 \mathrm{bBb}$ complex or accelerating the disassembly of pre-formed convertase, resulting in a block of the complement system cascade. This regulation inhibits and limits production of anaphylatoxins, including $\mathrm{C} 3 \mathrm{a}, \mathrm{C} 4 \mathrm{a}$ and C5a $(6,7)$. Although not in asthma, it has been demonstrated that NSAID blocks CD55 expression and is correlated with the 
$\mathbf{A}$

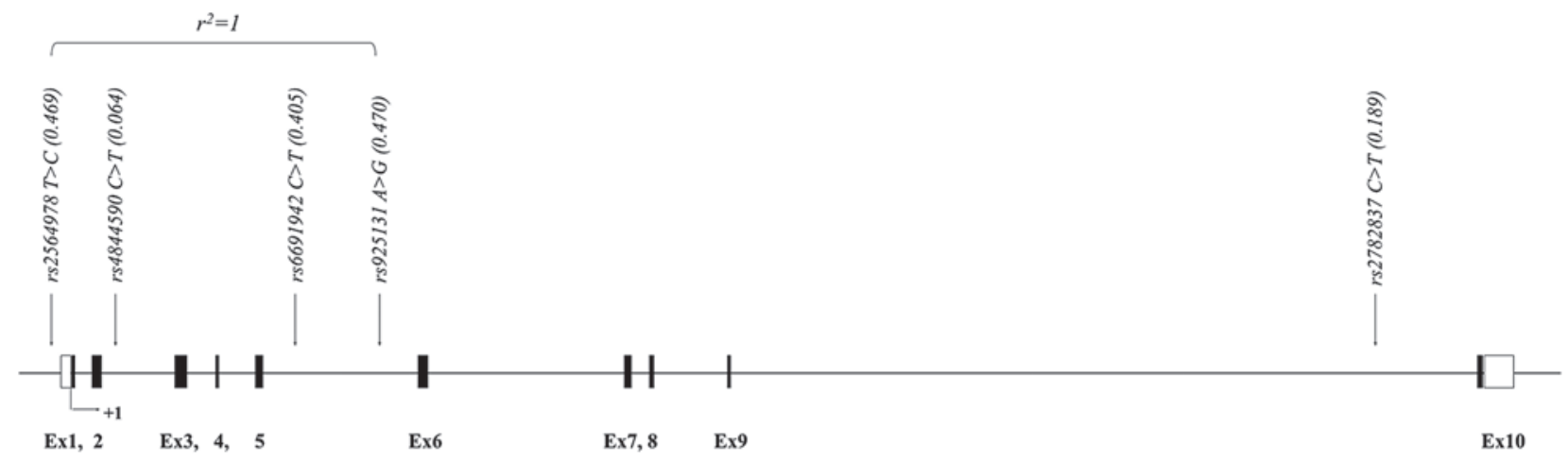

B

\begin{tabular}{|c|c|c|c|c|c|c|}
\hline Hap. & 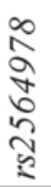 & 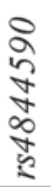 & 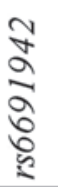 & $\begin{array}{l}\frac{\pi}{n} \\
\check{n} \\
\stackrel{a}{2}\end{array}$ & 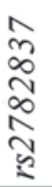 & Freq. \\
\hline$h t l$ & $\mathrm{C}$ & $\mathrm{C}$ & $\mathrm{T}$ & $\mathrm{G}$ & $\mathrm{C}$ & 0.365 \\
\hline$h t 2$ & $\mathrm{~T}$ & C & $\mathrm{C}$ & A & $\mathrm{C}$ & 0.363 \\
\hline$h t 3$ & $\mathrm{~T}$ & $\mathrm{C}$ & $\mathrm{C}$ & A & $\mathrm{T}$ & 0.199 \\
\hline ht4 & C & $\mathrm{T}$ & $\mathrm{C}$ & G & $\mathrm{C}$ & 0.068 \\
\hline$h t 5$ & $\mathrm{C}$ & $\mathrm{C}$ & $\mathrm{C}$ & A & $\mathrm{T}$ & 0.003 \\
\hline Others & - & - & - & - & - & 0.002 \\
\hline
\end{tabular}

Others includes: CCT GT and CT CAC
C

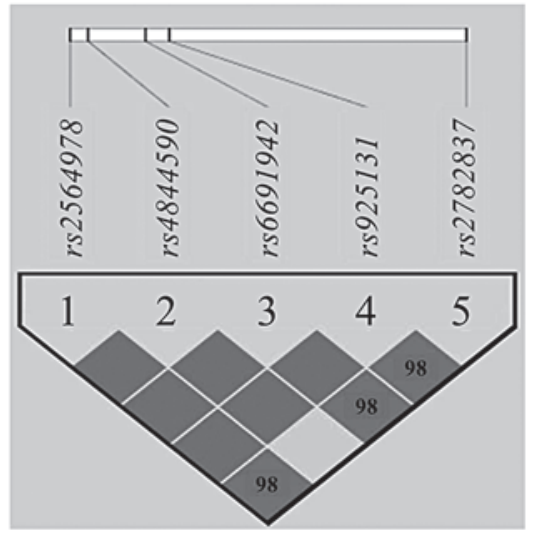

Figure 1. Schematic physical map, haplotypes and LD plot of CD55. (A) Polymorphisms identified in CD55. Coding exons are marked by shaded blocks and untranslated region (UTR) by white blocks. The LD coefficients $\left(\mathrm{r}^{2}\right)$ are based on the genotypes of Korean samples. (B) Haplotypes of $C D 55$ in the Korean population. Only those with frequencies over 0.05 are shown. (C) LD coefficients (ID'l and $\mathrm{r}^{2}$ ) among the selected SNPs based on the genotypes of whole study subjects in this study ( $\mathrm{n}=592)$. LD, linkage disequilibrium; SNP, single nucleotide polymorphism.

level of COX-1 (8). In line with these studies, we established a hypothesis that the polymorphisms in CD55 may cause AERD. Therefore, we examined the genetic association of CD55 polymorphisms with the risk of AERD.

\section{Materials and methods}

Study subjects. A total of 163 subjects with AERD and 429 aspirin-tolerant asthma (ATA) subjects were recruited from the Asthma Genome Research Center comprising hospitals of Soonchunhyang, Chonnam, Chungbuk, Seoul national and Chung-Ang Universities in Korea. Oral aspirin challenge (OAC) was performed with increasing doses of aspirin $(9,10)$. Briefly, patients with a history of aspirin hypersensitivity were provided with $30 \mathrm{mg}$ orally. Respiratory and nasal symptoms, blood pressure, external signs (urticaria and angioedema) and forced expiratory volume in $1 \mathrm{sec}\left(\mathrm{FEV}_{1}\right)$ were documented every $30 \mathrm{~min}$ for a period of $1.5 \mathrm{~h}$. In the absence of any indication of an adverse reaction after $1.5 \mathrm{~h}$, increasing dosages of aspirin (60, 100, 300 and $400 \mathrm{mg}$ ) were administered until the patient developed the reaction and the same measurements were repeated every hour. Those with no history of aspirin hypersensitivity were started on $100 \mathrm{mg}$ of aspirin and gradually the dosage was increased to $200 \mathrm{mg}, 350 \mathrm{mg}$ and $450 \mathrm{mg}$ until the patient developed the reaction. If no reaction occurred $4 \mathrm{~h}$ after the final dose, the test was deemed negative. Aspirin-induced bronchospasm, reflected by a decline (\%) in $\mathrm{FEV}_{1}$, was calculated as the pre-challenge $\mathrm{FEV}_{1}$ minus the post-challenge $\mathrm{FEV}_{1}$, divided by the pre-challenge $\mathrm{FEV}_{1}$. OAC reactions were categorized into three groups as follows: i) $15 \%$ or greater decrease in $\mathrm{FEV}_{1}$ or nasal reactions (AERD), ii) less than $15 \%$ decrease in $\mathrm{FEV}_{1}$ without naso-ocular or cutaneous reactions (ATA), or iii) less than $15 \%$ decrease in $\mathrm{FEV}_{1}$ with cutaneous reactions [aspirin-induced urticaria (AIU)]. All individuals provided informed consent to participate in the study. The methods were approved by the local ethics committees of hospital.

Single nucleotide polymorphism (SNP) selection and genotyping. We selected candidate polymorphic SNPs in the National Center for Biotechnology Information (NCBI; build 36) and the International HapMap Project (http://hapmap.ncbi.nlm. nih.gov/) based on the frequencies in the Asian population and linkage disequilibrium (LD) status. For examination of AERD risk association, a total of five polymorphisms were selected for this study. The location of the variants is indicated in the genetic map of CD55 as shown in Fig. 1A. Among the five SNPs, only 
Table I. Clinical profiles for association analysis between aspirin-exacerbated respiratory disease and control subjects.

\begin{tabular}{|c|c|c|c|}
\hline Clinical profile & Total no. of subjects & AERD & ATA \\
\hline Number of subjects & 592 & 163 & 429 \\
\hline Mean age (range) $)^{\mathrm{a}, \mathrm{c}}$ & $46.15(15.40-77.88)$ & $43.13(17.22-72.73)$ & $47.30(15.40-77.88)$ \\
\hline Height $(\mathrm{cm})$ & $160.78 \pm 8.63$ & $161.72(143.00-196.00)$ & $160.42(140.00-199.00)$ \\
\hline Weight (kg) & $62.81 \pm 10.84$ & $61.25 \pm 10.38$ & $63.40 \pm 10.97$ \\
\hline $\mathrm{FEV}_{1}$ decrease following aspirin challenge $(\%)^{\mathrm{b}}$ & $9.27 \pm 13.24$ & $24.63 \pm 16.11$ & $3.54 \pm 4.85$ \\
\hline Blood eosinophil (\%) & $6.01 \pm 5.73$ & $5.96 \pm 5.21$ & $6.03 \pm 5.92$ \\
\hline FVC \%, predicted & $88.54 \pm 14.08$ & $90.35 \pm 14.04$ & $87.85 \pm 14.05$ \\
\hline $\mathrm{FEV}_{1} \%$, predicted $^{\mathrm{a}}$ & $90.54 \pm 16.97$ & $87.58 \pm 16.94$ & $91.66 \pm 16.87$ \\
\hline PC20, methacholine $(\mathrm{mg} / \mathrm{ml})^{\mathrm{a}}$ & $6.43 \pm 8.67$ & $5.02 \pm 7.83$ & $6.91 \pm 8.90$ \\
\hline Total IgE (IU/ml) & $357.65 \pm 604.09$ & $348.60 \pm 596.44$ & $361.00 \pm 607.56$ \\
\hline Gender (male/female) & $206 / 386$ & $59 / 104$ & $147 / 282$ \\
\hline Current Smoker (\%) & 27.70 & 21.47 & 30.07 \\
\hline Positive rate of Nasal polyP $(\%)^{\mathrm{b}}$ & 33.83 & 57.89 & 26.06 \\
\hline Positive rate of skin test (\%) & 56.42 & 52.76 & 57.81 \\
\hline Positive rate of specific IgE (Df, \%) & 36.38 & 38.30 & 35.75 \\
\hline Positive rate of specific $\operatorname{IgE}(\mathrm{Dp}, \%)$ & 44.56 & 45.77 & 44.16 \\
\hline
\end{tabular}

AERD, aspirin-exacerbated respiratory disease; ATA, aspirin-tolerant asthma; Nasal polyP,nasal polyposis; FEV ${ }_{1}$, forced expiratory volume in $1 \mathrm{sec}$; FVC, forced vital capacity. ${ }^{\mathrm{a}} \mathrm{P}<0.05$; ${ }^{\mathrm{b}} \mathrm{P}<0.0001$ compared to ATA control; ${ }^{\mathrm{c}}$ age at first medical examination.

Table II. Association analysis of CD55 polymorphisms and haplotypes with risk of AERD.

\begin{tabular}{|c|c|c|c|c|c|c|}
\hline \multirow[b]{2}{*}{ Polymorphism } & \multicolumn{2}{|c|}{ Co-dominant } & \multicolumn{2}{|c|}{ Dominant } & \multicolumn{2}{|c|}{ Recessive } \\
\hline & OR $(95 \%$ CI $)$ & P-value & OR $(95 \% \mathrm{CI})$ & P-value & OR $(95 \%$ CI $)$ & P-value \\
\hline$r s 2564978 T>C$ & $1.10(0.85-1.42)$ & 0.47 & $0.98(0.66-1.47)$ & 0.93 & $1.34(0.87-2.06)$ & 0.18 \\
\hline$r s 4844590 C>T$ & $1.21(0.72-2.02)$ & 0.48 & $1.30(0.76-2.23)$ & 0.34 & - & 0.99 \\
\hline$r s 6691942 C>T$ & $1.05(0.81-1.37)$ & 0.7 & $0.97(0.66-1.42)$ & 0.87 & $1.26(0.78-2.04)$ & 0.35 \\
\hline$r s 925131 A>G$ & $1.09(0.85-1.42)$ & 0.5 & $0.97(0.65-1.46)$ & 0.9 & $1.33(0.87-2.05)$ & 0.19 \\
\hline$r s 2782837 C>T$ & $1.14(0.82-1.56)$ & 0.44 & $1.09(0.74-1.61)$ & 0.66 & $1.61(0.69-3.75)$ & 0.27 \\
\hline CD55_ht1 & $1.06(0.82-1.38)$ & 0.65 & $0.98(0.67-1.43)$ & 0.91 & $1.28(0.79-2.08)$ & 0.31 \\
\hline CD55_ht2 & $0.81(0.61-1.07)$ & 0.14 & $0.85(0.59-1.23)$ & 0.39 & $0.57(0.30-1.08)$ & 0.08 \\
\hline CD55_ht3 & $1.14(0.83-1.57)$ & 0.41 & $1.11(0.75-1.64)$ & 0.61 & $1.60(0.69-3.72)$ & 0.27 \\
\hline CD55_ht4 & $1.21(0.72-2.02)$ & 0.48 & $1.30(0.76-2.23)$ & 0.34 & - & 0.99 \\
\hline
\end{tabular}

AERD, aspirin-exacerbated respiratory disease; ATA, aspirin-tolerant asthma; OR, odds ratio; CI, confidence interval. The P-values and OR with $95 \% \mathrm{CI}$ of polymorphisms in a co-dominant model were reported in our previous genome-wide association study [Kim et al (9)].

one SNP ( $r s 2564978)$ is located in the promoter region while the other four SNPs (rs4844590, rs6691942, rs925131 and rs2782837) are located in introns of CD55 (Table II). The minor allele frequencies (MAFs) of all SNPs and allelic variations are listed in Table II. Genotyping was carried out with $20 \mathrm{ng}$ of genomic DNA using the TaqMan assay in the ABI prism 7900HT sequence detection system (Applied Biosystems, CA, USA) in 163 AERD cases and 429 ATA controls with the assessment of data quality by duplicate DNAs $(n=10)$.

Statistical analysis. We calculated LD in all the pairs of biallelic loci using Lewontin's D' (ID'I) (11) and $r^{2}$. PHASE algorithm (ver. 2.0), developed by as previously described by Stephens et al, was used for inferring haplotypes (12). Associations of genotypes and haplotypes in the CD55 gene with AERD were calculated using logistic analysis adjusted for age, gender, smoking status, atopy and body mass index (BMI) as covariates. We also performed linear regression analysis to determine the differences in the rates of decline in $\mathrm{FEV}_{1}$ following aspirin challenge among the genotypes and haplotypes. The data were adjusted, managed and analyzed using Statistical Analysis System (SAS) version 9.1 (SAS Inc., Cary, NC, USA). Statistical power was calculated by PGA (Power for Genetic Association analysis) software with 
Table III. Regression analysis of $C D 55$ polymorphisms and haplotypes with fall rate of $\mathrm{FEV}_{1}$ by aspirin provocation.

\begin{tabular}{lcccccc}
\hline Polymorphism & $\mathrm{C} / \mathrm{C}$ & $\mathrm{C} / \mathrm{R}$ & $\mathrm{R} / \mathrm{R}$ & $\mathrm{Pa}$ & $\mathrm{Pb}$ & $\mathrm{Pc}$ \\
\hline$r s 2564978 T>C$ & $172(9.30 \pm 12.79)$ & $285(8.94 \pm 13.49)$ & $135(9.78 \pm 13.26)$ & 0.88 & 0.87 & 0.66 \\
$r s 4844590 C>T$ & $518(9.17 \pm 13.17)$ & $71(10.17 \pm 13.63)$ & $3(-2.07 \pm 7.59)$ & 0.98 & 0.79 & 0.17 \\
$r s 6691942 C>T$ & $213(9.49 \pm 13.36)$ & $279(8.63 \pm 12.85)$ & $99(10.41 \pm 14.02)$ & 0.86 & 0.68 & 0.39 \\
$r s 925131 \mathrm{~A}>G$ & $171(9.32 \pm 12.82)$ & $284(8.95 \pm 13.51)$ & $135(9.78 \pm 13.26)$ & 0.88 & 0.87 & 0.67 \\
$r s 2782837 C>T$ & $393(9.08 \pm 13.58)$ & $172(8.83 \pm 11.82)$ & $25(13.95 \pm 16.30)$ & 0.40 & 0.76 & 0.10 \\
CD55_ht1 & $214(9.48 \pm 13.33)$ & $280(8.60 \pm 12.84)$ & $98(10.50 \pm 14.07)$ & 0.83 & 0.69 & 0.36 \\
CD55_ht2 & $255(9.51 \pm 13.20)$ & $266(9.60 \pm 13.47)$ & $71(6.88 \pm 12.25)$ & 0.35 & 0.70 & 0.18 \\
CD55_ht3 & $396(9.09 \pm 13.55)$ & $171(8.88 \pm 11.84)$ & $25(13.95 \pm 16.30)$ & 0.36 & 0.70 & 0.10 \\
CD55_ht4 & $518(9.17 \pm 13.17)$ & $71(10.17 \pm 13.63)$ & $3(-2.07 \pm 7.59)$ & 0.98 & 0.79 & 0.17 \\
\hline
\end{tabular}

C/C, common allele/common allele; C/R, common allele/rare allele; R/R, rare allele/rare allele; Pa, P-values of co-dominant model; $\mathrm{Pb}, \mathrm{P}$-values of dominant model; $\mathrm{Pc}, \mathrm{P}$-values of recessive model; $\mathrm{FEV}_{1}$, forced expiratory volume in $1 \mathrm{sec}$.

Table IV. Information of CD55 polymorphisms, minor allele frequencies of Korean AERD/ATA patients and controls from other populations.

\begin{tabular}{|c|c|c|c|c|c|c|c|c|c|}
\hline \multirow[b]{2}{*}{ Polymorphism } & \multirow[b]{2}{*}{ Heterozygosity } & \multirow[b]{2}{*}{ HWE } & \multirow{2}{*}{$\begin{array}{l}\text { Statistical } \\
\text { power }\end{array}$} & \multicolumn{2}{|c|}{$\begin{array}{l}\text { MAFs of } \\
\text { present study }\end{array}$} & \multicolumn{4}{|c|}{ MAFs of other ethnic groups } \\
\hline & & & & AERD & ATA & Caucasian & Chinese & Japanese & African \\
\hline$r s 2564978 T>C$ & 0.498 & 0.387 & 94.52 & 0.485 & 0.459 & 0.228 & 0.558 & 0.413 & 0.013 \\
\hline$r s 4844590 C>T$ & 0.120 & 0.767 & 38.41 & 0.074 & 0.059 & 0.305 & 0.044 & 0.089 & 0.167 \\
\hline$r s 6691942 C>T$ & 0.482 & 0.552 & 94.36 & 0.411 & 0.400 & 0.398 & 0.395 & 0.488 & 0.190 \\
\hline$r s 925131 A>G$ & 0.498 & 0.384 & 94.52 & 0.485 & 0.460 & 0.712 & 0.442 & 0.587 & 0.987 \\
\hline$r s 2782837 C>T$ & 0.307 & 0.138 & 81.99 & 0.204 & 0.181 & - & 0.256 & 0.170 & 0.000 \\
\hline CD55_ht1 & 0.481 & 0.601 & 94.34 & 0.411 & 0.397 & - & - & - & - \\
\hline CD55_ht2 & 0.451 & 0.837 & 93.35 & 0.313 & 0.361 & - & - & - & - \\
\hline CD55_ht3 & 0.305 & 0.119 & 81.83 & 0.202 & 0.179 & - & - & - & - \\
\hline CD55_ht4 & 0.120 & 0.767 & 38.41 & 0.074 & 0.059 & - & - & - & - \\
\hline
\end{tabular}

HWE, Hardy-Weinberg equilibrium; MAF, minor allele frequency; AERD, aspirin-exacerbated respiratory disease; ATA, aspirin-tolerant asthma. The MAFs of Caucasian, Chinese, Japanese and African populations were obtained from the dbSNP database of NCBI (http://www. ncbi.nlm.nih.gov/snp/).

$5.4 \%$ disease prevalence, relative risk of 1.3 and MAFs of our subjects and subject sizes $(13,14)$.

\section{Results}

Patients. A total of 592 asthma patients including 163 AERD cases and 429 ATA controls were recruited for analysis. The characteristics of the patients are summarized in Table I. Among the factors of diagnosis, percentage of $\mathrm{FEV}_{1}$ fall rate by aspirin provocation showed significant differences between the AERD and ATA groups $(24.63 \pm 16.11$ and 3.54 \pm 4.85 , respectively, $\mathrm{P}<0.0001$; Table I). In addition, predicted $\mathrm{FEV}_{1}$ and amount of PC20 methacholine also proved to be significantly different between AERD and ATA patients $(\mathrm{P}=0.05)$. The average value of predicted $\mathrm{FEV}_{1}$ was $87.58 \pm 16.94$ in AERD patients and $91.66 \pm 16.87$ in ATA patients (Table I), while the amount of PC20 methacholine was 5.02 \pm 7.83 and $6.91 \pm 8.90$ in AERD and ATA patients (Table I). For an adequate logistic regression analysis, gender, percentage of current smoking status, existence of atopy and BMI were adjusted.

Genotype distribution. We also calculated the genotype distributions and all loci were in Hardy-Weinberg equilibrium (Table IV, P>0.05). In addition, we established an LD plot and haplotypes using the five genotyped variants. LDs between each variant are shown in Fig. $1 \mathrm{C}$ and $\mathrm{r}^{2}=1$ is also displayed in Fig. 1A. Results of logistic analyses revealed that CD55 variants are not associated with the risk of AERD. P-values did not reach statistical significance in all genetic models $(\mathrm{P}>0.05)$. These data with odds ratios are summarized in Table III. In further regression analysis, we investigated the differences between allele distributions and the decline of $\mathrm{FEV}_{1}$ by aspirin provocation. However, we failed to find significant differences between allele distribution, including haplotypes and risk of 
AERD. P-values of each polymorphism showed no association signal higher than 0.05 in co-dominant, dominant and recessive models. The results of regression analysis are summarized in Table III.

\section{Discussion}

According to a hypothesis that AERD is not correlated with $\mathrm{IgE}$, immune responses including eosinophil infiltration are considered as important factors of AERD pathogenesis (15). Additionally, a previous study demonstrated that leukotriene molecules are correlated with an expression of complement receptors, including $\mathrm{C} 3 \mathrm{~b}$ (16). C3a and C5a play key roles in attraction of immune cells, including eosinophil (17). In addition, another group demonstrated that the inflammatory cytokines IL- 4 and IL-1 $\beta$ enhance the expression and release of CD55 (18). The cytokine is able to activate neutrophils, leading to CD55 expression on neutrophils (19). Therefore, the concentration of CD55 protein may affect the activity of eosinophils and neutrophils, which are important in AERD pathogenesis.

Previous studies have demonstrated that the pro-inflammatory mediators, including lipopolysaccharide, tumor necrosis factor- $\alpha$ and IL-1 $\beta$, regulate the expression level of CD55 $(18,20,21)$. In addition, it has been reported that the cyclooxygenase (COX)-2 pathway expressed in the inflammatory cells is also upregulated by the pro-inflammatory mediators (22). PG-E2, which is generated from the COX-1 and COX-2 pathways, modulates immune function through a variety of mechanisms $(23,24)$. Thus, $C D 55$ may affect the risk of AERD through the COX pathways.

The study by Kim et al (9) shows only the results from a co-dominant model of logistic analysis. However, in order to investigate a possible association between the CD55 SNPs and the risk of AERD in this study, we carried out more comprehensive analyses using dominant and recessive models. In addition, we performed a regression analysis using the fall rate of $\mathrm{FEV}_{1}$ due to aspirin provocation. However, although we have performed more thorough analyses, all of our results did not support our hypothesis. However, the comparison between allele frequencies in our subjects and other ethnic groups from dbSNP database shows that the allele frequencies of the SNPs were similar within the Asian population, but different when compared to those of Caucasian and African subjects (Table IV). Therefore, further studies with other ethnic groups are required to validate the exact function of CD55 polymorphisms in AERD.

In the present study, we used only common polymorphisms which have frequencies higher than 0.05. Thus, in order to validate the exact function of polymorphisms in $C D 55$, replication studies using rare variants which have frequencies lower than 0.05 may be required. Additionally, the average statistical power of the present study is $79.08 \%$, indicating that our sample size was not sufficient for this analysis. However, rarity of AERD makes it difficult to recruit sufficient patients for an analysis in Korean asthma cohorts. Thus, further study using larger independent groups and/or meta-analysis may be required to investigate the functions of CD55 gene further. In addition, a comparison between asthmatics and a healthy normal control is also needed for an full understanding of the gene.
In conclusion, we identified five SNPs in the human CD55 gene and explored the effect of polymorphisms in aspirin-exacerbated respiratory disease subjects in a Korean population. However, statistical analyses showed no association between polymorphisms in the promoter and intron and fall rate of $\mathrm{FEV}_{1}$. Despite the importance of CD55 protein in the immune system, we failed to find convincing evidence of association between polymorphisms in CD55 and development of AERD. Due to various limitations of the present study, further studies using a large independent population and rare alleles may be required. Although our P-values did not show significance, results from this study may be useful for future research in human airway diseases.

We failed to find evidence of association between polymorphisms in CD55 and risk of AERD in both logistic and regression analysis. However, various limitations of the present study, further studies using large independent population and rare alleles may be required. Although our P-values did not show significance, results from this study may be useful in the etiology of AERD and other bronchial diseases.

\section{Acknowledgements}

This study was supported by a National Research Foundation of Korea (NRF) grant funded by the Korean government (MEST; no. 2009-0080157 and no. 2010-0011206). This study was supported by a grant of the Korea Healthcare Technology R\&D Project, Ministry for Health, Welfare and Family Affairs, Republic of Korea (A010249). The DNA samples were generously provided by Soonchunhyang University, Bucheon Hospital Biobank (Seoul, Korea), a member of the National Biobank of Korea, supported by the Ministry of Health, Welfare and Family Affairs, Republic of Korea.

\section{References}

1. Widal F, Abrami P and Lermoyez J: Anaphylaxie et idiosyncrasie. 1992 [Anaphylaxis and idiosyncrasy. 1992]. Allergy Proc 14: 371-376, 1993.

2. Samter M and Beers RF Jr: Concerning the nature of intolerance to aspirin. J Allergy 40: 281-293, 1967.

3. Stevenson DD, Sanchez-Borges M and Szczeklik A: Classification of allergic and pseudoallergic reactions to drugs that inhibit cyclooxygenase enzymes. Ann Allergy Asthma Immunol 87: 177-180, 2001.

4. Pawankar R: Nasal polyposis: an update: editorial review. Curr Opin Allergy Clin Immunol 3: 1-6, 2003.

5. Szczeklik A and Stevenson DD: Aspirin-induced asthma: advances in pathogenesis, diagnosis, and management. J Allergy Clin Immunol 111: 913-921; quiz 922, 2003.

6. Liszewski MK, Farries TC, Lublin DM, Rooney IA and Atkinson JP: Control of the complement system. Adv Immunol 61: 201-283, 1996.

7. Turnberg D and Botto M: The regulation of the complement system: insights from genetically-engineered mice. Mol Immunol 40: 145-153, 2003.

8. Akhtar MS, Kousar F, Masood M, Fatimi S and Kokab: Evaluation of paclitaxel and carboplatin versus combination chemotherapy with fluorouracil, doxorubicin and cyclophosphamide as a neoadjuvant therapy in patients with inoperable breast cancer. J Coll Physicians Surg Pak 20: 748-752, 2010.

9. Kim BS, Park SM, Uhm TG, et al: Effect of single nucleotide polymorphisms within the interleukin- 4 promoter on aspirin intolerance in asthmatics and interleukin- 4 promoter activity. Pharmacogenet Genomics 20: 748-758, 2010.

10. Nizankowska-Mogilnicka E, Bochenek G, Mastalerz L, et al: EAACI/GA2LEN guideline: aspirin provocation tests for diagnosis of aspirin hypersensitivity. Allergy 62: 1111-1118, 2007. 
11. Hedrick PW: Gametic disequilibrium measures: proceed with caution. Genetics 117: 331-341, 1987.

12. Stephens M, Smith NJ and Donnelly P: A new statistical method for haplotype reconstruction from population data. Am J Hum Genet 68: 978-989, 2001.

13. Menashe I, Rosenberg PS and Chen BE: PGA: power calculator for case-control genetic association analyses. BMC Genet 9: 36, 2008.

14. Hedman J, Kaprio J, Poussa T and Nieminen MM: Prevalence of asthma, aspirin intolerance, nasal polyposis and chronic obstructive pulmonary disease in a population-based study. Int J Epidemiol 28: 717-722, 1999.

15. Nasser SM, Pfister R, Christie PE, et al: Inflammatory cell populations in bronchial biopsies from aspirin-sensitive asthmatic subjects. Am J Respir Crit Care Med 153: 90-96, 1996.

16. Nagy L,Lee TH, Goetzl EJ,Pickett WC and Kay AB: Complement receptor enhancement and chemotaxis of human neutrophils and eosinophils by leukotrienes and other lipoxygenase products. Clin Exp Immunol 47: 541-547, 1982.

17. Taube C, Rha YH, Takeda K, et al: Inhibition of complement activation decreases airway inflammation and hyperresponsiveness. Am J Respir Crit Care Med 168: 1333-1341, 2003.
18. Nasu J, Mizuno M, Uesu T, et al: Cytokine-stimulated release of decay-accelerating factor (DAF;CD55) from HT-29 human intestinal epithelial cells. Clin Exp Immunol 113: 379-385, 1998.

19. Berger M and Medof ME: Increased expression of complement decay-accelerating factor during activation of human neutrophils. J Clin Invest 79: 214-220, 1987.

20. Heine H, El-Samalouti VT, Nötzel C, et al: CD55/decay accelerating factor is part of the lipopolysaccharide-induced receptor complex. Eur J Immunol 33: 1399-1408, 2003.

21. Andoh A, Fujiyama Y, Sumiyoshi K, Sakumoto H, Okabe H and Bamba T: Tumour necrosis factor-alpha up-regulates decayaccelerating factor gene expression in human intestinal epithelial cells. Immunology 90: 358-363, 1997.

22. Stevenson DD: Aspirin sensitivity and desensitization for asthma and sinusitis. Curr Allergy Asthma Rep 9: 155-163, 2009.

23. Harris SG, Padilla J, Koumas L, Ray D and Phipps RP: Prostaglandins as modulators of immunity. Trends Immunol 23: 144-150, 2002.

24. Goodwin JS and Ceuppens JL: Effect of nonsteroidal antiinflammatory drugs on immune function. Semin Arthritis Rheum 13. 134-143, 1983. 